\title{
Outcome of Very Low Birth Weight Neonates in a Tertiary Level Hospital Outside Capital of Bangladesh: A Study in Faridpur Medical College Hospital
}

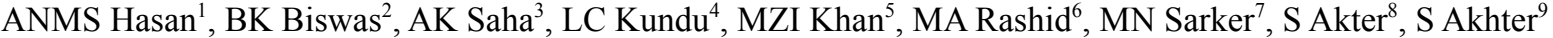

\begin{abstract}
:
Very low birth weight (VLBW) is an important cause of infant mortality and still a challenge for achieving Millennium Development Goal (MDG) in Bangladesh. Our study was to see the risk factors and its outcome of VLBW neonates in a tertiary level Faridpur Medical College Hospital (FMCH), outside capital Dhaka. This prospective cross sectional study was conducted in neonatal Unit of pediatric department in FMCH. All neonates who were admitted here had been selected and we find out the very low birth weight neonates for our study purpose. All anthropometric measurements were taken by us in our department. We took all the informations about neonates within our study period of six months (November 2013 to April 2014) through a prescribed protocol. Total 1126 neonates admitted within our study period of 6 months. Among 1126 neonates 76 of them were VLBW. Among 76 VLBW neonates $38(50 \%)$ were male and $38(50 \%)$ were female, but 22 of them were expired, which was $28.94 \%$ of total VLBW neonates. Most expired on month of March which was 38.46\%. Among expired VLBW neonates 10 $(45.45 \%)$ of them were male and $12(54.55 \%)$ of them were female. Total $48(63.15 \%)$ mothers of VLBW neonates delivered at hospital of them Caesarean section occurs in $40(52.63 \%)$ mothers of VLBW neonates and normal vaginal delivery (NVD) occurs in 36 cases (47.37\%). Home delivery occurs in mothers of 28 VLBW neonates. Among them $15(53.57 \%)$ were done by traditional birth attendance (TBA), $8(28.57 \%)$ by local dai and $5(17.86 \%)$ by relatives of the family of VLBW neonates. We found mothers of $41(53.95 \%)$ VLBW neonates had premature rupture of membrane (PROM), 8 (10.53\%) had eclampsia, 4 (5.26\%) had leaking membrane and $4(5.26 \%)$ had history of accident. Maternal age of VLBW neonates are more common between 18 to 24 years of age that was $53.95 \%$ (41 in number) but 27 mothers $(35.52 \%$ ) were below 18 years of age. We found in our study that the survival rate of VLBW neonates in our institute is not like developed countries but it is better than many developing countries around the world.
\end{abstract}

Key words: Very low birth weight, Neonate, PROM, Caesarean section.

\section{Introduction:}

Infants with very low birth weight are one of the highest risk pediatric patient populations.

1. Dr. ANM Saiful Hasan, MBBS, Medical Officer, Department of Pediatrics, Faridpur Medical College Hospital, Faridpur, Bangladesh.

2. Dr. Barun Kanti Biswas, MBBS, FCPS (Pediatrics), Associate Professor and Head, Department of Pediatrics, Faridpur Medical College, Faridpur.

3. Dr. Alok Kumar Saha, MBBS, FCPS (Pediatrics), Associate Professor, Department of Pediatrics, Faridpur Medical College, Faridpur.

4. Dr. Lakshman Chandra Kundu, MBBS, MCPS, DCH, MD (Pediatrics), Associate Professor, Department of Pediatrics, Faridpur Medical College, Faridpur.

5. Dr. Mohammad Zahirul Islam Khan, MBBS, MPH, DCH, Assistant Registrar, Department of Pediatrics, Faridpur Medical College Hospital, Faridpur.

6. Dr. M A Rashid, MBBS, Medical Officer, Department of Pediatrics, Faridpur Medical College Hospital, Faridpur.

7. Dr. Mst. Naznin Sarker, MBBS, FCPS (Pediatrics), Junior Consultant, Department of Pediatrics, Faridpur Medical College Hospital, Faridpur.

8. Dr. Tahmina Akter, MBBS, MD (Pediatrics), Assistant Professor and Head, Department of Paediatrics, Diabetic Association Medical College, Faridpur.

9. Dr. Shahnaz Akter, MBBS, FCPS (Gynae \&Obs), Registrar, AdDin Medical College and Hospital, Mogbazaar, Dhaka.

Address of correspondence :

Dr. ANM Saiful Hasan, MBBS, Medical Officer, Department of

Pediatrics, Faridpur Medical College Hospital, Faridpur, Bangladesh.

Phone : +880 1726662484, E-mail : drsaifulpdn@gmail.com
One in 4 very low birth weight (VLBW) infants $(<1500 \mathrm{gm})$ dies in the first year of life; nearly all deaths $(87 \%)$ occur in the first month ${ }^{1}$. VLBW infants who survive have higher rates of morbidity and disability, including developmental delays and cognitive impairment, than infants with normal birth weights $^{2-5}$. By birth weight, infants under 2,500gm are categorized as low birth weight infants (LBW). Among these LBW infants, those under 1,500gm are categorized as very low birth weight infants (VLBW), and infants under $1,000 \mathrm{gm}$ as extremely low birth weight infants $(\mathrm{ELBW})^{6-7}$. These infants need special care and treatments such as neonatal special care because they have high morbidity and mortality rates. Therefore, managing these neonates to survive without complication will ultimately be the most important method in reducing neonatal mortality rate. With the advancement of neonatal care allow survival of extremely Preterm infants, who are prone to arrange of long term complications in comparison to their term counterparts $^{8-11}$. There is concern that improved rates of survival of very low birth Weight (VLBW), and particularly extremely low birth weight (ELBW) infants, may be associated with increased rates of neuro developmental handicap ${ }^{12}$, although some report improved survival without increased handicap ${ }^{13}$. There are many reports of factors affecting early survival of VLBW infants. The survival rate of VLBW infants 
worldwide ranges between $43 \%$ in developing countries such as Jamaica ${ }^{14}$ to more than $90 \%$ in developed countries, such as the Netherlands ${ }^{15}$, in India it is $63 \%{ }^{16}$.

The purpose of this study was to find out the risk factors and survival rate of VLBW neonates in Special Care of Neonatal Unit (SCANU) at Pediatric department of Faridpur Medical College Hospital, a government tertiary level hospital outside the capital of Bangladesh. There was no enough previous study on VLBW outcome in a peripheral tertiary hospital in Bangladesh.

\section{Materials and Methods:}

This was a prospective cross sectional study conducted in neonatal Unit of pediatric department in FMCH. All neonates who were admitted here had been selected. Among them we found out the very low birth weight neonates for our study purpose. We took all the informations about neonates within our study period of six months (November 2013 to April 2014). All informations have been documented in hospitals admission and discharge books and treatment papers of the patients. A structured questionnaire was prepared in light of the objectives. The purpose of the study was clearly explained to the respondents prior to taking informed consent from them. The data were analyzed by using the Statistical Package for the Social Sciences (SPSS), version 16.0.

\section{Results:}

Total 1126 neonates were admitted within our study period of 6 months. Among them 727 were male and 399 were female. We found out VLBW neonates from them \& collected our information. Among 1126 neonates 76 of them were VLBW, i.e. $6.75 \%$ of total neonates who were admitted within our study period. In every month a significant number of neonates were admitted in pediatric department. Among them November and March had highest admission, both had 198 admissions each. Among 76 VLBW neonates 38 $(50 \%)$ were male and $38(50 \%)$ were female (Table-I).

Table-I: Distribution of very low birth weight (VLBW) baby according to months

\begin{tabular}{lll}
\hline Month & Total & VLBW (Male, Female) \\
\hline November & 198 & $2(1,1)$ \\
December & 178 & $18(7,18)$ \\
January & 193 & $16(8,8)$ \\
February & 184 & $8(4,4)$ \\
March & 198 & $13(8,5)$ \\
April & 175 & $19(10,9)$ \\
Total & $1126(100 \%)$ & $76(38,38)(6.75 \%)$ \\
\hline
\end{tabular}

Among 76 VLBW neonates 22 of them were expired i.e. $28.94 \%$ of total VLBW neonates. Among them most expired on March which was 38.46\% Among 22 (28.95\%) expired VLBW neonates 10 of them were male and 12 of them were female. That was $45.45 \%$ and $54.55 \%$ respectively. (Table-II).

Table-II: Distribution of VLBW neonates expired during study period

\begin{tabular}{llll}
\hline Month & $\begin{array}{l}\text { Total VLBW } \\
\text { baby }\end{array}$ & $\begin{array}{l}\text { Expired } \\
\text { baby(Male, } \\
\text { Female) }\end{array}$ & $\begin{array}{l}\text { Percentage (Male, } \\
\text { November }\end{array}$ \\
\hline December & 2 & $1(1,0)$ & $50 \%$ \\
January & 16 & $6(1,5)$ & $33.33 \%$ \\
February & 8 & $4(2,2)$ & $25 \%$ \\
March & 13 & $2(1,1)$ & $25 \%$ \\
April & 19 & $5(3,2)$ & $38.46 \%$ \\
Total & 76 & $4(2,2)$ & $21.05 \%$ \\
& & $22(10,12)$ & $28.94 \%(45.45 \%$, \\
\hline
\end{tabular}

Table III shows among 76 VLBW neonates 48 $(63.15 \%)$ were delivered at hospital and 28 (36.85\%) were delivered at home.

Table-III: Distribution of VLBW neonates according to place of delivery

\begin{tabular}{ll}
\hline Place of delivery & VLBW neonate (\%) \\
\hline Hospital & $48(63.15)$ \\
Home & $28(36.85)$ \\
Total & $76(100)$ \\
\hline
\end{tabular}

Table IV shows total caesarean section occurs in $40(52.63 \%)$ mothers of VLBW neonates and normal vaginal delivery (NVD) occurs in 36 cases $(47.37 \%)$.

Table-IV: Distribution of VLBW neonates according to mode of delivery

\begin{tabular}{ll}
\hline Mode of delivery & VLBW neonate (\%) \\
\hline Caesarean section & $40(52.63)$ \\
Normal Vaginal Delivery(NVD) & $36(47.37)$ \\
Total & $76(100)$ \\
\hline
\end{tabular}

Table-V shows total 28 VLBW neonates had home delivery. Among them 15 (53.57\%) were done by traditional birth attendance (TBA), $8(28.57 \%)$ by local dai and $5(17.86 \%)$ by relatives of the family of VLBW neonates. 
Table-V: Distribution according to Birth Attendant of Home delivery.

\begin{tabular}{ll}
\hline Performed by & VLBW neonate (\%) \\
\hline TBA & $15(53.57)$ \\
Dai & $8(26.57)$ \\
Relatives & $5(17.86)$ \\
Total & $28(100)$ \\
\hline
\end{tabular}

Table-VI shows among mothers of 76 VLBW neonates $19(25 \%)$ had no diseases or problems, $41(53.95 \%)$ had premature rupture of membrane (PROM), $8(10.53 \%)$ had eclampsia, $4(5.26 \%)$ had leaking membrane and 4 $(5.26 \%)$ had history of accident.

Table-VI: Distribution of VLBW neonates according to maternal problems

\begin{tabular}{|c|c|}
\hline Maternal problems & VLBW neonate (\%) \\
\hline $\begin{array}{l}\text { Premature rupture of membrane } \\
\text { (PROM) }\end{array}$ & 41 (53.95) \\
\hline Eclampsia & $8(10.53)$ \\
\hline Leaking membrane & $4(5.26)$ \\
\hline Accident & $4(5.26)$ \\
\hline No problem & $19(25)$ \\
\hline Total & 76 (100) \\
\hline
\end{tabular}

Table-VII shows maternal age of VLBW neonates are more common between 18 to 24 years of age that was $53.95 \%$ (41 in number) but 27 mothers (35.52\%) were below 18 years of age, only $10.53 \%$ were 25 years and above.

Table-VII: Distribution of VLBW neonates according to maternal age.

\begin{tabular}{ll}
\hline Maternal age & Number (\%) \\
\hline Below 18 years & $27(35.52)$ \\
18 years to 24 years & $41(53.95)$ \\
25 years and above & $8(10.53)$ \\
\hline
\end{tabular}

Table-VIII shows $4(5.26 \%)$ mothers had gestational age within 34 to 36 weeks and 14 (18.42\%) had gestational age below 28 weeks but in majority of mother of VLBW neonates gestational age were within 28 weeks to 34 weeks.
Table-VIII: Distribution of VLBW neonates according to maternal gestational age

\begin{tabular}{ll}
\hline Gestational age & VLBW neonate (\%) \\
\hline 36 completed weeks and above & -- \\
34 completed weeks upto 36 & $4(5.27)$ \\
weeks & \\
28 weeks upto 34 weeks & $58(76.31)$ \\
Below 28 weeks & $14(18.42)$ \\
\hline
\end{tabular}

Table-IX shows birth weight of 55 (72.37\%) VLBW neonates were within $1001 \mathrm{gm}$ to $1500 \mathrm{gm}, 20$ $(26.31 \%)$ were within $800 \mathrm{gm}$ to $1000 \mathrm{gm}$ and 1 $(1.31 \%)$ was below $800 \mathrm{gm}$.

Table-IX: Distribution according to birth weight of VLBW neonates

\begin{tabular}{ll}
\hline Birth weight & Number () \\
\hline $1001 \mathrm{gm}-1500 \mathrm{gm}$ & $55(72.37)$ \\
$800 \mathrm{gm}-1000 \mathrm{gm}$ & $20(26.31)$ \\
Below $800 \mathrm{gm}$ & $1(1.31)$ \\
\hline
\end{tabular}

Table-X shows $93.42 \%$ mother had their $1^{\text {st }}$ parity while $6.58 \%$ had their second parity.

Table-X: Distribution according to parity of the mother of VLBW neonates

\begin{tabular}{ll}
\hline Parity & Number (\%) \\
\hline $1^{\text {st }}$ parity & $71(93.42)$ \\
$2^{\text {nd }}$ parity & $5(6.58)$ \\
$3^{\text {rd }}$ or more & $0(0)$
\end{tabular}

\section{Discussion:}

In millennium development goal (MDG) maternal health and infant mortality are two vital indicators which are achieved by our country and that was recognized by United Nation (UN). The global prevalence of LBW is $15.5 \%$, but $96.5 \%$ of them in developing countries. There is a significant variation in LBW incidence rates across the United Nations regions, with the highest incidence in South-Central Asia $(27.1 \%)$ and the lowest in Europe $(6.4 \%)^{17-18}$. The result of our study shows $6.75 \%$ of neonate that were VLBW. Among them 28.95\% expired during the treatment period. So, $71.05 \%$ of VLBW neonate survived after management in this hospital. The survival rate of VLBW infants worldwide ranges between $43 \%$ in developing countries such as Jamaica ${ }^{19}$ to more than $90 \%$ in developed countries, such as 
the Netherlands ${ }^{20}$. The mortality rate for VLBW infants in Soweto, Johannesburg, between 2000 and 2002 was reported at $71 \%{ }^{21}$.

There has been gradual improvement in the survival of VLBW infants in developed and developing countries all over the world. From $81 \%$ in 1986 to $90.3 \%$ in 1998 in New Zealand ${ }^{22}$ and from $62 \%$ in 1993 to $81.6 \%$ in $2003^{23}$ in a developing country like Malaysia. Our country also improving in VLBW outcome in tertiary level hospitals and in specialized hospitals.

Our study shows among 76 VLBW neonates 48 of them $(63.15 \%)$ were delivered at hospital and 28 of them $(36.85 \%)$ were delivered at home. So, home delivery still is at higher rate here, although here hospital delivery includes private clinics, primary, secondary and tertiary level hospitals. The 2005 Lao Reproductive Health Survey found that among children born in the last 5 years, approximately $85 \%$ of births occurred at home ${ }^{24}$. In Nigeria, approximately $67 \%$ of births occur at home ${ }^{25}$. Total $64 \%$ of pregnant women (74\% rural and $43 \%$ urban) in Pakistan deliver at home $^{26}$. In developed countries all babies born at hospital care facilities.

Our study finds out caesarean section occurs in 40 $(52.63 \%)$ mothers of VLBW neonates and normal vaginal delivery (NVD) occurs in 36 cases $(47.37 \%)$. So, caesarean section was a very high level incidence, which was more than half of all very low birth weight neonate delivered. Although rates of caesarean section in many countries have increased from the recommended level of $15 \%$ in developed and many developing countries ${ }^{27}$, its rate is very high in our study. In Iran in 2000 the rate of caesarian section was $35 \%$.

We found, among 76 VLBW neonate mothers, 19 (25\%) had no disease or problem, 41 (53.95\%) had premature rupture of membrane (PROM), 8 (10.53\%) had eclampsia, $4(5.26 \%)$ had leaking membrane and 4 $(5.26 \%)$ had history of accident. The mothers of VLBW neonates who had no disease they had to maintain whole family or doing physical work.

We also found total 28 VLBW neonates had home delivery. Among them $15(53.57 \%)$ were done by traditional birth attendance (TBA), 8 (28.57\%) were done by local dai and $5(17.86 \%)$ were done by relatives of the family of VLBW neonates. One study found that since 2005 in Lao Peoples Democratic Republic, $63.4 \%$ of babies were delivered with the assistance of relatives compared to only $12.1 \%$ with traditional birth attendants. Health professionals assisted in $18.5 \%$ of births $8.1 \%$ were assisted by a doctor, $3.5 \%$ by a nurse, $3 \%$ by a midwife and $3.9 \%$ by a health worker ${ }^{24}$.
Our study shows maternal age of VLBW neonates are more common between 18 to 24 years of age that was $53.95 \%$ (41 in number) but 27 mothers (35.52\%) were below 18 years of age, only $10.53 \%$ were 25 years and above. In Dhaka Shishu Hospital, it was found that the incidence of LBW was $46.08 \%$ among the young mothers (20-25 years), which is supported by another study conducted at the same hospital which showed an incidence rate of $34.31 \%$ among mothers below 20 years of age ${ }^{29}$.

We also found $4(5.26 \%)$ mothers had gestational age within 34 to 36 weeks and $14(18.42 \%)$ had gestational age below 28 weeks but majority of mother of VLBW neonates gestational age were within 28 weeks to 34 weeks. We did not find any VLBW neonates above 37 weeks of gestational age.

During our study period we found birth weight of 55 $(72.37 \%)$ VLBW neonates were within 1001 grams to 1500 grams, $20(26.31 \%)$ were within $800 \mathrm{gm}$ to 1000 gm and $1(1.31 \%)$ was below $800 \mathrm{gm}$. The VLBW neonates who was below 800 grams he was a male child and his mother was primi.

To see the parity we found $93.42 \%$ mother had their $1^{\text {st }}$ parity while $6.58 \%$ had their second parity. We did not find any $3^{\text {rd }}$ parity mothers having VLBW neonates.

\section{Conclusion:}

Bangladesh is a developing country with limited health resources and high patient numbers; it is not possible to provide full tertiary support to every VLBW infant outside the capital. Our study is to see the VLBW babies who are admitted in tertiary level hospital outside the capital of Bangladesh and their outcome after proper management in hospital. This study also tries to find out a significant relationship between VLBW and other factors like age of the mother, socioeconomic status of the family, gestational age of the baby. 


\section{References :}

1. Mathews TJ, Minino AM, Osterman MJK, Strobino DM, Guyer B. Annual Summary of Vital Statistics 2008. Pediatrics. 2011; 127(1):145-57.

2. Eichenwald EC, Stark AR. Management and Outcomes of Very Low Birth Weight. The New England Journal of Medicine. 2008; 358(16):1700-1711.

3. Boardman JD, Powers DA, Padilla YC, Hummer RA. Low Birth Weight, Social Factors, and Developmental Outcomes among Children in the United States.Demography. 2002; 39(2):353-368.

4. Hack M, Flanney DJ, Schluchter M, Cartar L, Borawski E, Klein $\mathrm{N}$. Outcomes in young adulthood for very-low-birth-weight infants. New England Journal of Medicine. 2002; 346(3):150-57.

5. U.S. Department of Health and Human Services HRaSA, Maternal and Child Health Bureau. Child Health USA 2010.

6. World Heath Organization (WHO) Prevention of perinatal morbidity and mortality Public Health Papers No-42, Geneva, WHO, 1969.

7. World Heath Organization (WHO) Methodology of reporting and analysis of perinatal and maternal morbidity and mortality Recommendations of World Health Organization, Expert Committee, Bristol,WHO,1972.

8. Marlow N. Neurologic and developmental disability at six years of age after extremely preterm birth. N Engl J Med. 2005, 352(1):9-19.

9. Aylward GP. Neuro developmental outcomes of infants born prematurely J Dev Behav Pediatr. 2005, 26(6):427-40.

10. Brevaut-Malaty V. Longitudinal follow-up of a cohort of 350 singleton infants born at less than 32 weeks of amenorrhea neurocognitive screening, academic outcome, and perinatal factors. Eur Obstet Gynecol Reprod Biol. 2010.

11. Marlow N. Motor and executive function at 6 years of age after extremely preterm birth. Pediatrics 2007; 120(4):793-804.

12. Claas MJ. Two-year neuro developmental outcome of preterm born children?750g at birth. Arch Dis Child Fetal Neonatal 2010.

13. Riley K. Survival and neuro developmental morbidity at 1year of age following extremely preterm delivery over a20-year period: a single centre cohort study. Acta Paediatr. 2008, 97(2):159-65.

14. Trotman H, Bell Y. Neonatal sepsis in very low birth weight infants at the University Hospital of the West Indies. West Indian Med J. 2006; 55:165-9.

15. Anthony S, Ouden L, Brand R, Verloove-Vanhorick P, Gravenhorst JB. Changes in perinatal care and survival in very preterm and extremely preterm infants in The Netherlands between 1983 and 1995. Eur J Obstet Gynecol Reprod Biol. 2004; 112:170-7.

16. Basu S, Rathore P, Bhatia BD. Predictors of mortality in very low birth weight neonates in India. Singapore Med J. 2008; 49:55660 .

17. Lawn JE, Cousens S, Zupan J. Four million neonatal deaths: When? Where? Why? Lancet 2005; 365:891-900.

18. Kawser CA, Islam MN, Selina K. Maternal and socioeconomic risk factors associated with low birth weight. Bangladesh J Child Health. 1995; 19:112-13.
19. Trotman H, Bell Y. Neonatal sepsis in very low birth weight infants at the University Hospital of the West Indies. West Indian Med J. 2006; 55:165-9.

20. Anthony S, Ouden L, Brand R, Verloove-Vanhorick P, Gravenhorst JB. Changes in perinatal care and survival in very preterm and extremely preterm infants in The Netherlands between 1983 and 1995. Eur J obstet Gynecol Reprod Biol. 2004; 112:170-7.

21. Velaphi SC, Mokhachane M, Mphahlele RM, Beckh-Arnold E, Kuwanda ML, Cooper PA. Survival of very-low-birth-weight infants according to birth weight and gestational age in a public hospital. S Afr Med J. 2005; 95:504-9.

22. Darlow BA, Cust AE, Donoghue DA. Improved outcomes for very low birth weight infants: evidence from New Zealand national population based data. Arch Dis Child Fetal Neonatal Ed. 2003, 88:F23-F28.

23. Ho JJ, Chang AS. Changes in the process of care and outcome over a 10- year period in a neonatal nursery in a developing country. J Trop Pediatr. 2007; 53:232-7.

24. National Statistical Centre: Lao Reproductive Health Survey 2005. Vientiane Capital: Committee for Planning and Investment (CPI); 2007.

25. Ogunniyi SO, Faleyin BL, Makinde ON, Adejuyigbe EA, Ogunniyi FA, Owolabi AT. Delivery care services utilization in an urban population, Nigerian Journal of Medical 2000; 9(3)81-85.

26. Farid M, Jaferey AN, Ahsan A, Sheraz A. Adult and maternal mortality. Pakistan Demographic and Health Survey 2006-2007; NIPS, USAID. Islamabad, Pakistan: Crystal Printers 2008,167-81.

27. World Health Organization. Appropriate technology for birth. Lancet $1985 ; 2: 436-7$.

28. Ahmadnia S, Delavar B, Einizinab H, Kazemipour S, Mehryar AH, Naghavi M. Caesarean section in the Islamic Republic of Iran: prevalence and some Socio demographic correlates. Eastern Mediterranean Health Journal 2009;15(6):1389-98.

29. Rahman H. Pregnancy outcome and perinatal mortality in a primary health care project. Dhaka Shishu Hosp J. 1987;3:1-9. 